\title{
B 3108435
}

Bradshaw Lecture DECEMBER IOII.

R. Clement lucas. 

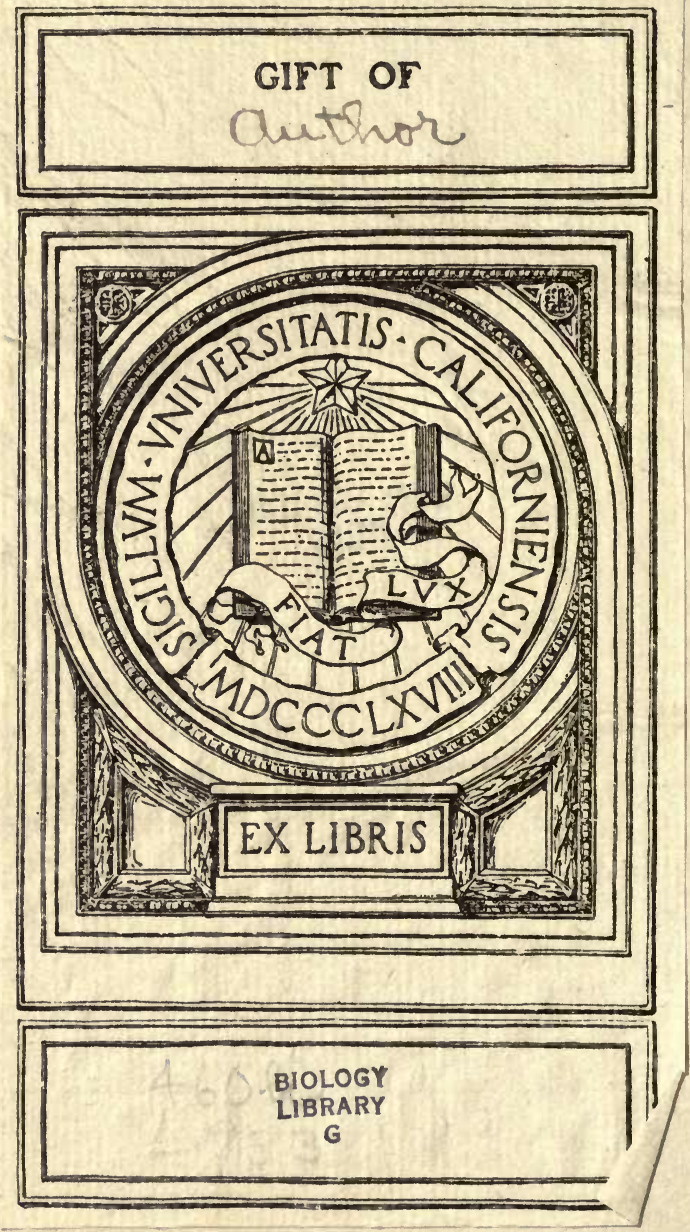



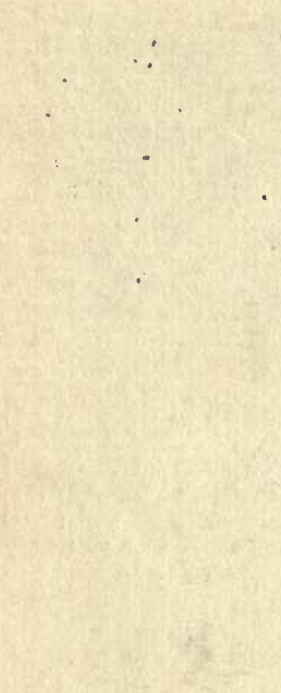


THE

\section{BRADSHAW LECTURE}

\section{ON SOME POINTS IN HEREDITY}

Delivered before the Royal College

of Surgeons of England on

DeCEMBer 6TH, 1911

BY

R. CLEMENT LUCAS, B.S., M.B.Lond., F.R.C.S.

CONSULTING SURGEN TO GUY'S HOSPITAL, AND TO THE EVELINA HOSPITAL FOR CHILDREN; MEMBER OF THE COUNCIL AND RECENTLY VICE-PRESIDENT OF THE

ROYAL COLLEGE OF SURGEONS OF ENGLAND; MEMBER OF THE SOCIÉTÉ DE CHIRURGIE OF PARIS; FELLOW, AND MEMBER OF THE COUNCIL, OF THE ROYAL SOCIETY OF MEDICINE; FORMERLY LECTURER ON SURGERY AND ON ANATOMY IN THE MEDICAL SCHOOL, OF GUY'S HOSPITAL

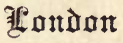

ADLARD AND SON, BARTHOLOMEW PRESS

BARTHOLOMEW CLOSE, E.C. 


$$
\begin{aligned}
& 41+43 \\
& 495
\end{aligned}
$$

BIOLơ̆Gy

LIBRAFY

Sipt of 
TO THE MEMORY OF A DEAR FRIEND

WALTER MOXON, M.D., F.R.C.P. PHYSICIAN TO GUY'S HOSPITAL

\section{WHO RECEIVED ME INTO HIS HOUSE WHEN I FIRST COMMENCED MY PROFESSIONAL STUDIES, AND WHO TAUGHT ME TO CULTIVATE THE FACULTY OF EXACT OBSERVATION BOTH IN ANATOMY AND CLINICAL RESEARCH \\ THIS LECTURE IS DEDICATED \\ IN GRATITUDE \\ BY THE AUTHOR}





\section{THE BRADSHAW LECTURE}

Mr. President and Gentlemen,-There is, perhaps, nothing more remarkable in comparing the teaching of former years with that of the present day, than to note the gradual recession and disuse of the word diathesis, as the true microbic cause of disease after disease becomes unravelled.

\section{Criticism of Diathesis.}

This word was used to indicate a constitutional condition derived from the parents, rendering a person liable to a particular disease-a disease developed from the tissues conveyed to him by his parentage. Lecturers spent many hours in elaborating details of such diatheses as the strumous, cancerous, syphilitic, gouty, rheumatic, nervous, plethoric, lymphatic, and so on. But after a time it became evident that the types described as characteristic were those in which a particular disease or habit had already com- 
menced its work. And now they have passed away like a dream, from which the slumberer awakes to enter into new realms of thought. Yet great was their influence, and mighty were the struggles made by observers to force their irregular cases under the unsympathetic wings of some particular diathesis.

\section{The Gouty Diathesis.}

Of these, the gouty is almost the last survivor, bolstered up by its aristocratic relations, and even more by the parvenu's wealth, waiting, as I believe, only for the discovery of a particular ferment which causes the precipitation of sodium urate in the most used joint of an overfed and perhaps bibulous person.

In this relation it may be interesting to quote Professor Laycock's account of the diathesis of the revered founder of this great museum. The Professor of Medicine of Edinburgh thus describes his brother Scot:

John Hunter was of the strumous arthritic diathesis with a nervous element also. [A little mixed you will observe.] His florid complexion indicated the vascular element, while his rounded forehead, thickened alæ nasi, thick upper lip, and caries teeth in the upper jaw marked the strumous tendency. 
He then proceeds to account for these hereditary defects :

John Hunter, it is clear, owed his strumous arthritic diathesis to the circumstance that his father was in his seventieth year when John was conceived and had at least one of the diseases of the gouty habit, namely, "gravel."

\section{He sums up :}

He was a typical man of his diathesis; with a predisposition to tuberculosis and atheroma, he, nevertheless, from the vigorous nutrition of his nervous system, was capable of great mental labour.*

Such is the libellous description given of the greatest surgeon of his day. $\dagger$

\section{Tuberculosis.}

Of diseases believed to be hereditary, the constitutional origin of none was taught with more dogmatic certainty than tuberculosis before the discovery of Koch's bacillus; and even now, though the various modes of entry and the

* 'Medical Times and Gazette,' vol. i, 1862.

+ The arthritic diathesis has been deprived of acute rheumatism by the discovery of the Diplococcus rheumaticus, and if $\mathrm{Mr}$. Goadby's observations prove correct as to a bacillus connected with tooth-sockets (published in 'The Lancet' of March 11th, 1911) being the cause of osteoarthritis, the diathesis will be still further depleted. 
manner of its distribution have long been studied, it is difficult to disentangle men's thoughts from this erroneous teaching. So deeply was this view of its constitutional origin instilled in the minds of the profession that acute observers shut their eyes to the most obvious cases of infection; yet there must have been some sceptics even in those days of darkness, for I find the late Sir Samuel Wilks writing in the 'Guy's Hospital Reports,' for 1869 as follows :*

It does appear most remarkable that whilst many of us have been speaking in the most positive terms of the inherited causes of consumption, there have been those who have no hesitation in looking upon it as a disease, like smallpox, accidentally introduced from without.

These believers in an outside cause were at that time in a hopeless minority. The great text-book authority, Sir Thomas Watson, thundered out his opinion as follows :

Is phthisis contagious? No, I verily believe it is not. A diathesis is not communicable from person to person; nor is the disease ever imparted to another, even by one scrofulous individual to another.

He then proceeds to explain away a most obvious instance of infection :

* "On the Nature and Causes of Disease," 'Guy's Hospital Reports,' 1869, p. 19. 
A wife watches the deathbed of her consumptive husband, and presently sinks herself under consumption; and there may be no tubercle or acknowledged examples of scrofula in her pedigree. Yet even here the latent diathesis may fairly be presumed to have existed. Very few families are perfectly free from strumous intermixture.

Could the blinding effect of a predominant theory be more clearly exposed than by this explanation?

There is no such thing as hereditary tuberculosis. We are dealing with a disease both infectious and inoculable, the bacillus of which has been known for thirty years. During that period better hygiene, housing, and food have reduced the mortality due to tuberculosis from 25 to 10 in every 1000 . By complete segregation the disease could be as certainly stamped out as hydrophobia was by the courageous muzzling order of Mr. Walter Long, to whom all honour is due. Of what service is it to inquire whether one family is more liable than another to this disease, when all are liable, and 97 per cent. of 500 consecutive autopsies were found by Naegeli to show evidence that tubercular infection had at one time taken place. Statistics to prove an hereditary predisposition are useless, unless taken of persons removed immediately after birth from the tubercle-infected 
house, and from contact with relatives already infected.

\section{Syphilis.}

Another diathesis we were taught was the syphilitic, but we know now that there is no such thing as hereditary syphilis. This is an inoculable disease, the organism causing which was discovered by Schaudinn in 1905, and it may be transmitted through the mother to her child when the placental protection breaks down, but there is no reliable evidence of its ever having been carried on to a third generation. It is a disease distributed by folly and reaped by innocence, and those well-meaning people who discovered in this disease a Divine scourge to be carried on to the third and fourth generations must be disappointed by its limits. The moment the Spirochrta pallida was demonstrated, it became evident that as the greater could not be carried by the less, direct transmission from the male to the ovum was out of court. The mother must first be infected, though the disease may not have been noticed, and Colles's law, which states that a mother cannot be inoculated on the nipple by her syphilitic infant, receives additional support by this discovery. It also emphasises the 
importance of directing attention especially to the treatment of the mother in order that the children may be born free from the disease.

\section{Leprosy.}

Of diseases assumed to be hereditary none has carried this reputation through a longer period than leprosy, which was regarded as hereditary as far back as Biblical times; and this belief will be kept in remembrance by Elisha's curse on his servant Gehazi: "The leprosy, therefore, of Naaman shall cleave unto thee, and unto thy seed for ever." Its contagiousness was also recognised from the earliest times, so that lepers became outcasts, and segregation has for centuries been the means employed to prevent the spread of the disease. Hansen discovered the Bacillus lepræ in 1871. An Indian commission failed to trace histories of the disease in the families of more than $\check{5}$ or 6 per cent.; children born of leprous parents are not leprous, and if removed from their parents seldom become so. This, again, is a disease which has been placed among ordinary contagious diseases, as the result of modern discoveries, and the belief in its hereditary transmission which held sway for tens of centuries has been scattered to the winds. 


\section{Malaria.}

Not many years ago malaria was described as a climatic diathesis, by which it was intended to imply that a constitutional condition was brought about by residence in certain climates, and that it became hereditary. The protozoon of malaria was discovered by Laveran in 1880 , and its life history and mode of inoculation has since been so clearly demonstrated that any idea of its being associated with a diathesis would strike everyone now as being utterly absurd.

\section{Cancer.}

The diathesis of cancer was never asserted with the same absolute confidence as was that of tuberculosis, and the profession has been about equally divided as to whether it was an hereditary disease or not. Sir James Paget taught that it was a blood disease, which caused local manifestations, but the evidence of its commencement as a local disease is now overwhelming. John Birkett, at one time a great authority, going over his cases, found cancer more common in families without history of cancer than in those families in which there was a history of the disease, and Paget could only trace a family history in one 
in three of his private patients, and one in five or six among hospital patients; whilst Harrison Cripps, thirty-three years ago, showed that if the evidence of heredity derived from collaterals and doubtful cases were excluded, there remained only a number similar to that expressing the normal frequency of cancer to the whole population. Dr. Bashford states that among persons over the age of thirty-five the chance that a man will die of cancer is one in eleven, and of a woman above the same age one in eight; and so great is the frequency of cancer as a cause of death above that age, that in one of every two families a parent or a grandparent will, on an average, have died of cancer. The influence of heredity in man must therefore be regarded as insignificant. It is true that by careful selection and in-breeding Dr. Bashford has produced a race of mice more liable to spontaneous cancer than those of a sound stock, but he warns us that experiment shows that those of cancerous stock are not more liable to implanted cancer than others.

To my mind we arrived half-way to the discovery of the cause of cancer when it was shown that the disease was inoculable in animals of the same species. We are dealing with a mildly con- 
tagious disease slowed down by age. This conceded, many observations fall readily into line. Thus Sir Henry Butlin's cases indicating that the instances on which heredity was based were all on either the father's or on the mother's side, would admit of the explanation that these individuals were more intimately associated, and so more liable to contagion. It explains the occurrence of several instances in the same house. It explains also the death of husband and wife of the same disease, of which I will mention three instances. A lady was operated on for cancer of the uterus, subsequently her husband died of cancer of the liver, and later she died of recurrence of the original disease. A gentleman I frequently meet in the City is one of six sons, all living and healthy, whose ages range between fifty-three and seventy. His father died at the age of fifty-seven from cancer of the rectum, his mother at sixty-one of cancer of the breast. He had one sister, who lived with her parents, and attended them in their last illnesses. She died of cancer of the breast, and what makes the probability of contagion stronger is the fact that the nurse also developed cancer, and died from it.

I operated on a lady in 1898 with so extensive 
a recurrence in the axilla that I removed both axillary artery and vein in dissecting out the growth. The wound healed primarily and she had no recurrence; but five years later she died of acute ptomaine poisoning from eating potted meat at a ball supper. A post-mortem examination showed no evidence of cancer anywhere, but there was extensive ulcerative colitis. Her husband subsequently died of cancer of the rectum.

The tendency of modern workers is to regard the cancer-cell, produced by irritation, as the fons et origo mali, and this has recently been very forcibly put by Sir Henry Butlin, but I am loth to accept such a hopeless hypothesis, as there is nothing analogous to it in the whole field of medicine. The forces of Nature are always directed to safeguarding the individual against attacks from without which may weaken health or endanger life. To produce a cell which wars against its parent and brings about self-destruction is contrary to every law of Nature.

If chronic irritation were alone sufficient to produce cancer millions of people who wear boots ought to have cancer of the little toe, which is practically unknown. It is chronic irritation, plus abrasion, that is required-in other words a 
surface through which a pathogenetic organism may find its entrance. Then the abrasion of the middle-aged woman's plump breast by the upper edge of her corset, the eczema of the nipple, the clay pipe sore of the lower lip, the tooth ulcer of cheek or tongue, the syphilitic and smoker's sores of the tongue, the chimney-sweep's sores of the scrotum, the burns caused on the Kashmiri's abdomina by the wearing of charcoal ovens, the chronic ulcers which become malignant, the X-ray eczema leading to epithelioma, are only means of entry for an organism yet to be discovered.

\section{A Question in Eugenics.}

I pass now from my destructive criticism of what were formerly believed to be diathetic diseases, but have been proved to be due to organisms penetrating from without, to make a few remarks on diseases of the nervous system with the object of alluding to a question in eugenics. Those who study mental diseases would have us believe that nothing is more certain than the hereditary tendency to the reproduction of nervous diseases, nor anything more disastrous than the results of in-breeding of tainted stocks. When criminals repeat their kind, and recurrent forms of lunacy 
occur, with lucid intervals, in which children are conceived only to be a burden on the rates, the State may perhaps determine to interfere to protect itself in the future.

By the kindness of Dr. Mott I show two pedigrees indicating the classes among which State interference might be considered justifiable.

Admitted to Cane Hill for attempted suicide by poison; Patient IV

An epileptic ; attempted suicide in 1874 by cutting her left arm; was taken to Colney Hatch, where she still remains

Committed suicide by cutting his left arm and dying from hæmorrhage.

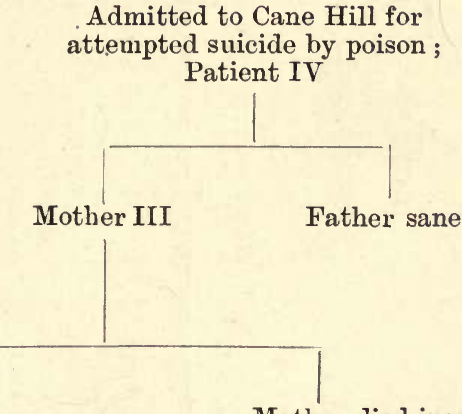
Father II
Mother died insane

children (three males and one female); all con- Mother died fined in lunatic asylums insane

Father I Mother committed suicide; cut her left arm and died from hæmorrhage

One of these shows suicide in four generations 


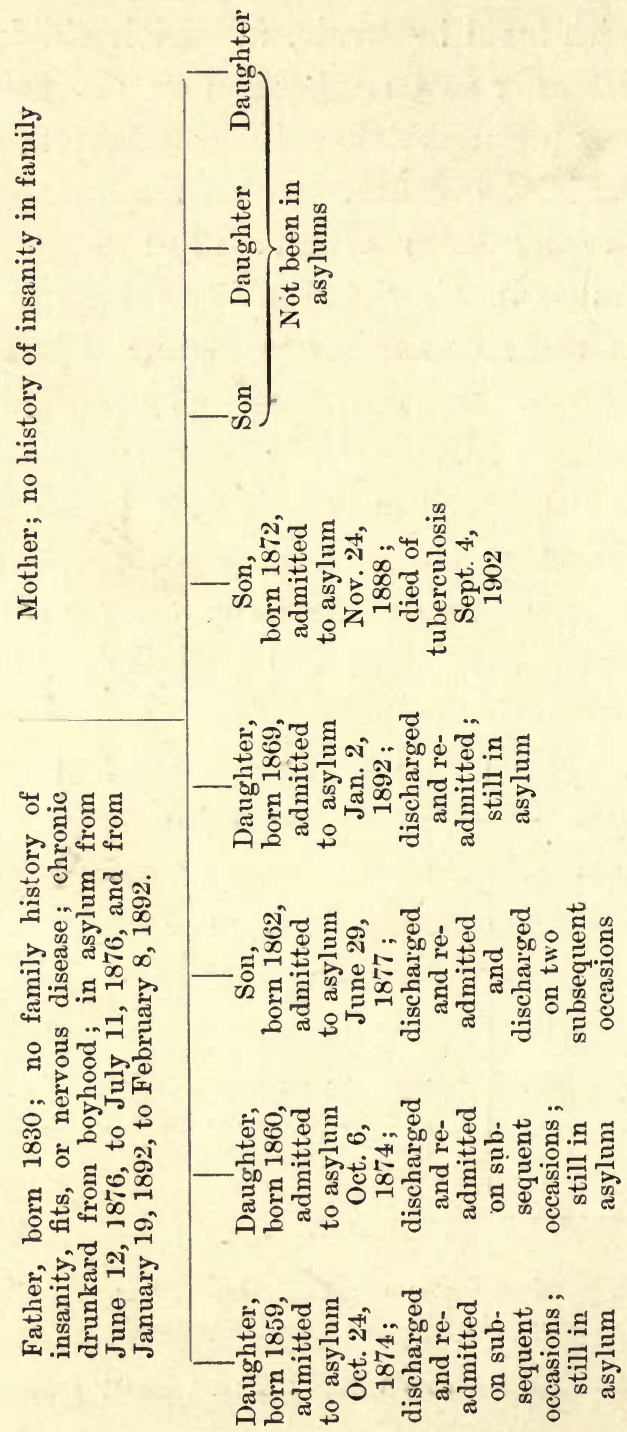


and all the offspring were lunatics. The other is the pedigree of a man subject to recurrent lunacy, who when out of the asylum continued to increase his family. Altogether he had eight children, five of whom were confined in asylums (see pedigrees, pp. 17 and 18).

I do not suppose for a moment that in a country such as this, where emotion plays so prominent a part in politics, that any operative measures such as have been adopted in one of the States of America would find favour. But political ideas gradually change. The "liberty of the individual" which was for a generation a great party cry has passed into oblivion, and we have in its place the political maxim that the minority must yield in everything to the will of the majority. This would therefore seem to be a favourable time for medical men to press on the Government measures for the protection of the State against the gradual increase of lunacy, and especially of criminal lunacy.

In this relation I would remark that the germinal organs (testes and ovaries) do not, actually belong to the individual, but to the next generation. As soon as they have determined his adult form they cease to be of service in his economy; and at times prove of great incon- 
venience, being not infrequently a cause of disease and of death. They are given him on trust for his descendants, and so badly does he often perform the duties of trustee that the blackest of bubble company promoters may appear innocent by comparison. If this view be accepted, and I maintain it is true in every respect, there should be less hesitation in employing humane and reasonable means for protecting the race. Within the last few years, and quite by accident, it has been discovered that exposure to the $\mathrm{X}$ rays destroys the reproductive function of the generative organs without injury to the individual. We have, therefore, a humane method at our command, which is not only painless, but so insidious that it might, if necessary, be applied without the knowledge of the individual. It probably would also be of service to him in assisting him to maintain his mental stability in after years.

I now leave this somewhat uninviting subject to say a few words on twins, on whom I have a few observations to record.

\section{Twiss.}

The liability to the production of twins can, I think, be shown to be hereditary. It may be due to an excessive fecundity on the part of the 
female, or it may be caused by a tendency to the division of a fertilised ovum, which tendency may be transmitted either by the male or female parent.' Mr. Rooth, in describing his case of Brighton united twins, gives the following family history :

The grandmother of the children had four separate births of twins as well as other children, and was herself a twin. The mother of these children was one of these twins.**

That is, he records four generations of twins on the female side.

The following case, as indicating the influence of the male parent, I give on the authority of Dr. Wormell, formerly headmaster of the Cowper Street Schools : An intimate friend and neighbour married, and his wife on two occasions gave birth to twins. After the second birth the wife died. Subsequently the gentleman married again, and his second wife gave birth to twins. In all these cases each pair of twins was of the same sex.

Among domesticated animals twins are encouraged in sheep, because the greater the number of lambs the greater the profit as mutton, so ewes which throw habitually only one lamb are weeded out of a flock. On the other hand, among cows the profit is from the milk, and a cow that gives * 'Brit. Med. Journ.,' Septem ber 23rd, 1911, p. 654 . 
birth to twins falls into disgrace and is fatted and killed for beef, because the farmer sells the milk which is in excess of what is required for the calf. Twin calves are therefore very rare. Breeders also recognise the male influence, and if many ewes throw single lambs as the result of conception to a particular ram, that ram is discarded.

\section{Dissimilar and Identical T'uins.}

There are two forms of twins generally recognised. In one there has been a simultaneous, or nearly simultaneous, fertilisation of two ova, an ovim descending probably from each ovary at the same menstrual period. Such twins may differ in sex, in height, in appearance and in disposition, presenting only the general resemblance of brothers and sisters. The other form is believed to result from the division of an ovum after all the elements for development are complete. These are invariably of the same sex and are enclosed in the same membranes. In height, appearance, and character they so closely resemble each other as to be often spoken of as "identical" twins. Shakespeare in "Twelfth Night" was guilty of confusing the first form with the second, when he founded the plot of his play on the 
resemblance betwen Sebastian and Viola as if they were identical twins.

\section{Identical Twins.}

I am able to give some remarkable facts concerning identical twins who entered as medical students at the same date and passed the examinations of the Royal Colleges and those of the M.B. and B.S.(Lond.) at the same time. After the Intermediate M.B. list was published, I was able to find out their numbers, and by what some might consider a curious coincidence, the totals of a large number of marks in anatomy given for two papers, dissections, and two tables of $v i v \hat{\imath}$ voce examination proved to be identical.

Identical Twins.

Intermediate M.B. Earamination in Anatomy.

\begin{tabular}{|c|c|c|c|c|c|c|c|}
\hline & 施高 & 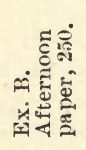 & 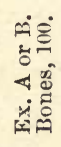 & 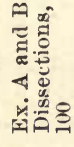 & 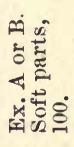 & $\begin{array}{l}\text { Total, } \\
800 .\end{array}$ & Passed. \\
\hline $\mathrm{Xa}$ & 145 & $8 \tilde{}$ & 65 & 35 & 75 & 405 & 2nd D. \\
\hline $\mathbf{X b}$ & 140 & 110 & 45 & 35 & 75 & 405 & 2nd $\mathrm{D}$. \\
\hline
\end{tabular}

'Taken alone, too much stress must not be laid upon the fact that their marks totalled the same, 


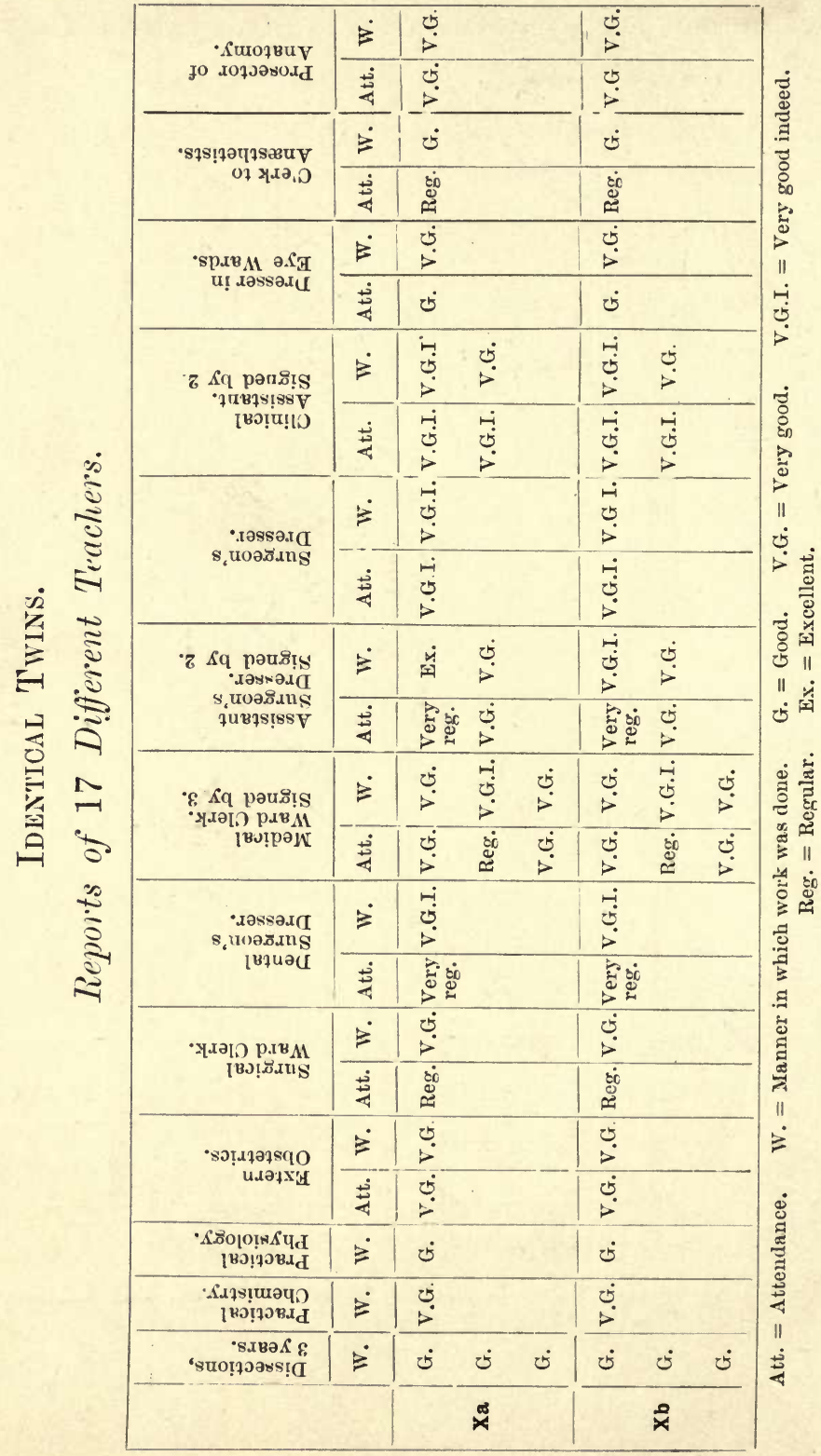


as among a large number of candidates this is sure to happen occasionally. But the table on p. 24 signed by seventeen different teachers, signing altogether thirty-three times for each student, shows a uniformity which could not be the result of accident. Out of all these sixty-six signatures, there is but one variation. One teacher put " excellent" instead of "very good indeed," terms regarded at the hospital as equivalent. In the opinion, therefore, of seventeen teachers, the abilities of these twins were indistinguishable or identical.*

\section{Dissimilar T'uins.}

The difference between twins developed from fertilisation of separate ova may be emphasised by disease occurring in one whilst the other escapes. Dr. R. Hutchison exhibited at the Children's Section of the Royal Society of Medicine twin brother and sister, aged a year and a half, the girl being the subject of well-marked achondroplasia whilst the boy was healthy.

A photograph of these he has kindly allowed me to reproduce (see Fig. 1, p. 26).

By the kindness of Dr. Shuttleworth I am also able to show a photograph of twin patients of Dr.

* For another case of identical twins see Appendix. 


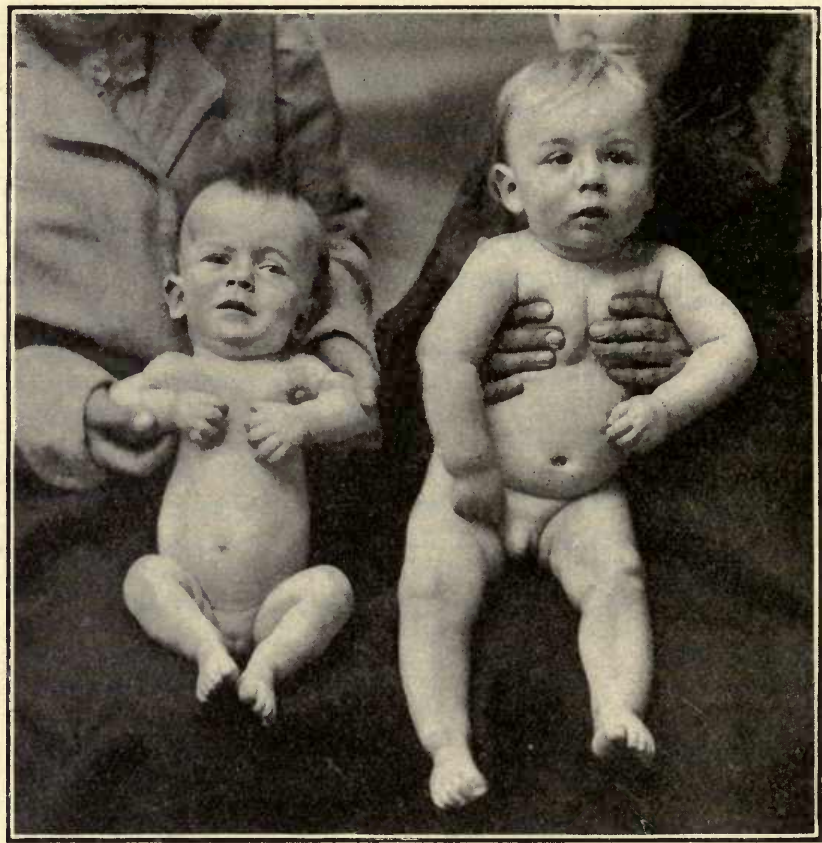

FIG. 1.-Achondroplasia in a twin.

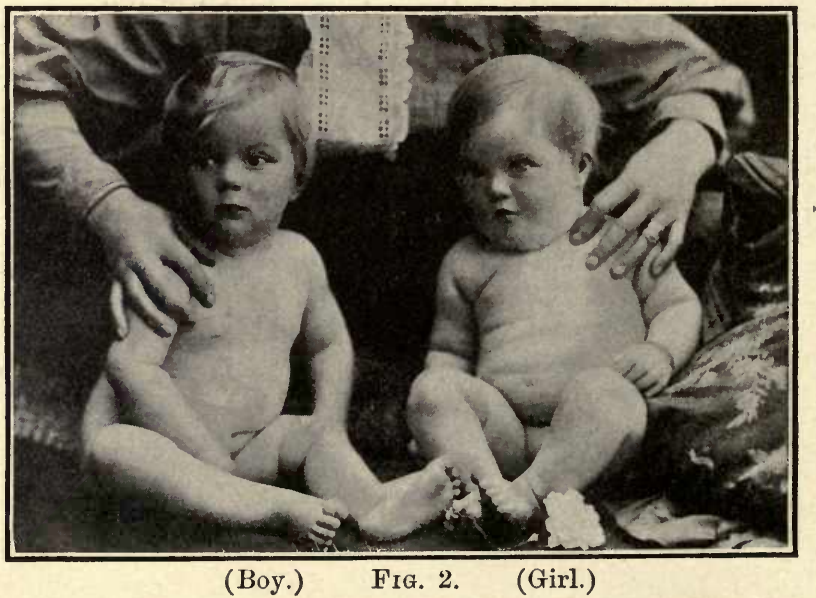


A. Jeffrys Wood, of Melbourne, by which it will be seen that the boy is normal and intelligent while the girl is a Mongoloid idiot (see Fig 2, p. 26).

A third case, lent me by Dr. Futchison, makes

Fig. 3.

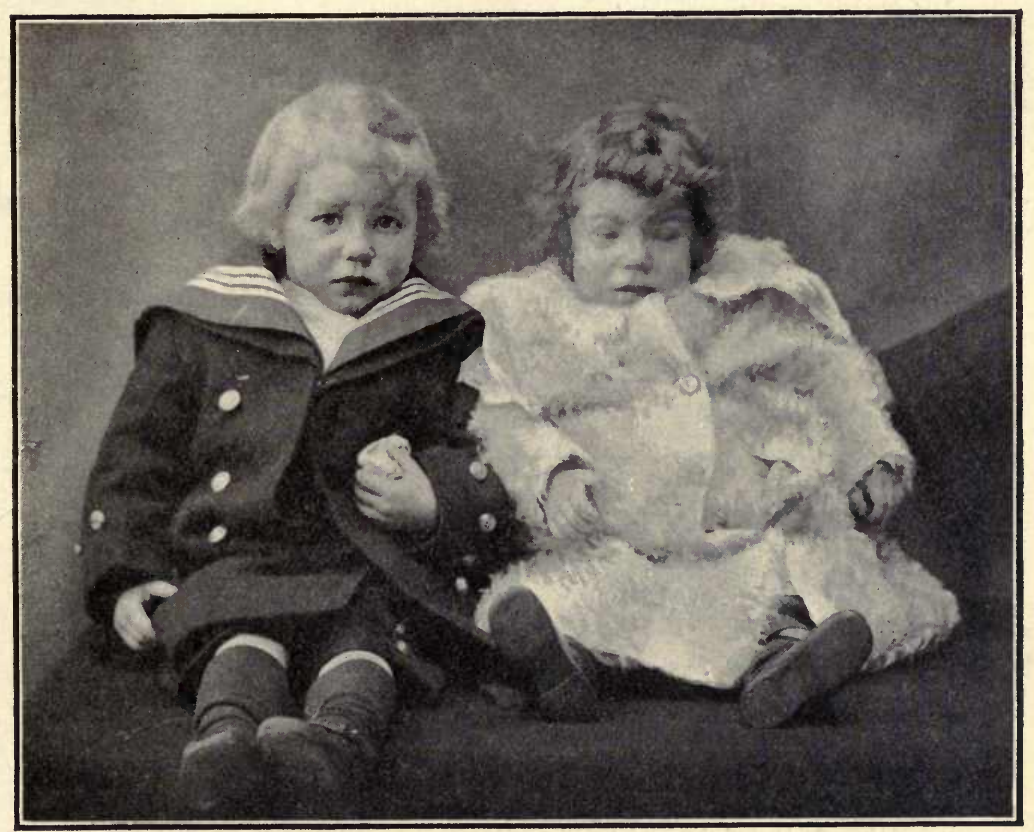

'T'wins-one a cretin.

the contrast still more evident, the boy being bright and intelligent, whilst the girl is a cretin showing a Mongoloid fold (see Fig. 3).

It is interesting to note that in all these three 
cases, the girl is the one that shows the defect, whilst the boy escapes.

From these cases it will be seen that neither in sex, mental development, nor tendency to disease need there be any resemblance. These are known as dissimilar twins.

Modrin Views on Heliedity.

It is almost impossible to allude to the various defects and deformities, known to be hereditary, without referring to the two modern schools of research, the Mendelian and Galtonian or biometrical school, each of which is doing excellent work in its own sphere, but can see no virtue whatever in the work of the other. 'To those trained in biology, the Mendelian researchès offer a fascinating inducement to further study, and appear to give a rational explanation of the occurrence of variations which breed true. But the precision that Mendel was able to give to his researches by crossing peas, so that he was able accurately to predict numerical results, can never occur among human beings, since such close inbreeding and back-breeding never occur in any human community. It is, nevertheless, much to anticipate approximate results.

The study of Mendelism is essentially a study 
of cross-breeding: yet when in the human race a negro unites with a white, the result is a halfcaste or mulatto. So also when a European unites with an Indian, the result is a Eurasian. Mulattoes united in marriage should, according to Mendelian law, segregate out into pure blacks, pure whites, and intermediates, but they do not; they continue to produce mulattoes, and Eurasians continue to produce Eurasians.

The Galtonian or biometrical school rely upon a statistical method of investigation. By collecting a large number of measurements or observations they gain material from which to deduce laws of heredity. Galton began by taking height, and maintained that what was true of one quality would probably prove true of all. His statement that half the heritage of a child is derived from his two parents, one quarter from the four grandparents, and one sixteenth from the great-grandparents, is so well known that I only mention it in passing. Professor Karl Pearson, repeating these observations, did not find the progression so regular, but the main results were not very dissimilar. Much has been done in this school since those early days, and the probabilities of many qualities have been worked out.

It will be gathered from my critical remarks 
on the old diatheses that I greatly dread the effect of a predominant theory; for if we are impressed by its truth, we are too liable unconsciously to accept what tallies with it, and reject that with which it does not agree. How otherwise could such giants in observation have made such extraordinary and obvious mistakes in the past?

\section{A Pedigrele on Thirty Years Ago.}

It may be interesting now to show a pedigree that I buried in the 'Guy's Hospital Reports' just thirty years ago, because its publication was long before the modern schools of heredity came into existence. I will leave it to you to judge whether it does or does not agree with the views of modern investigators. It is a pedigree of supernumerary digits associated with two other deformities, webbing of fingers and toes, and an occasional development of cleft palate. I can vouch that every possible care was taken to make it accurate, and where there was any doubt as to sex a neutral cross was used throughout the family. The man who furnished it was also of exceptional intelligence and he traced the deformity for us through five generations. It illustrates further 


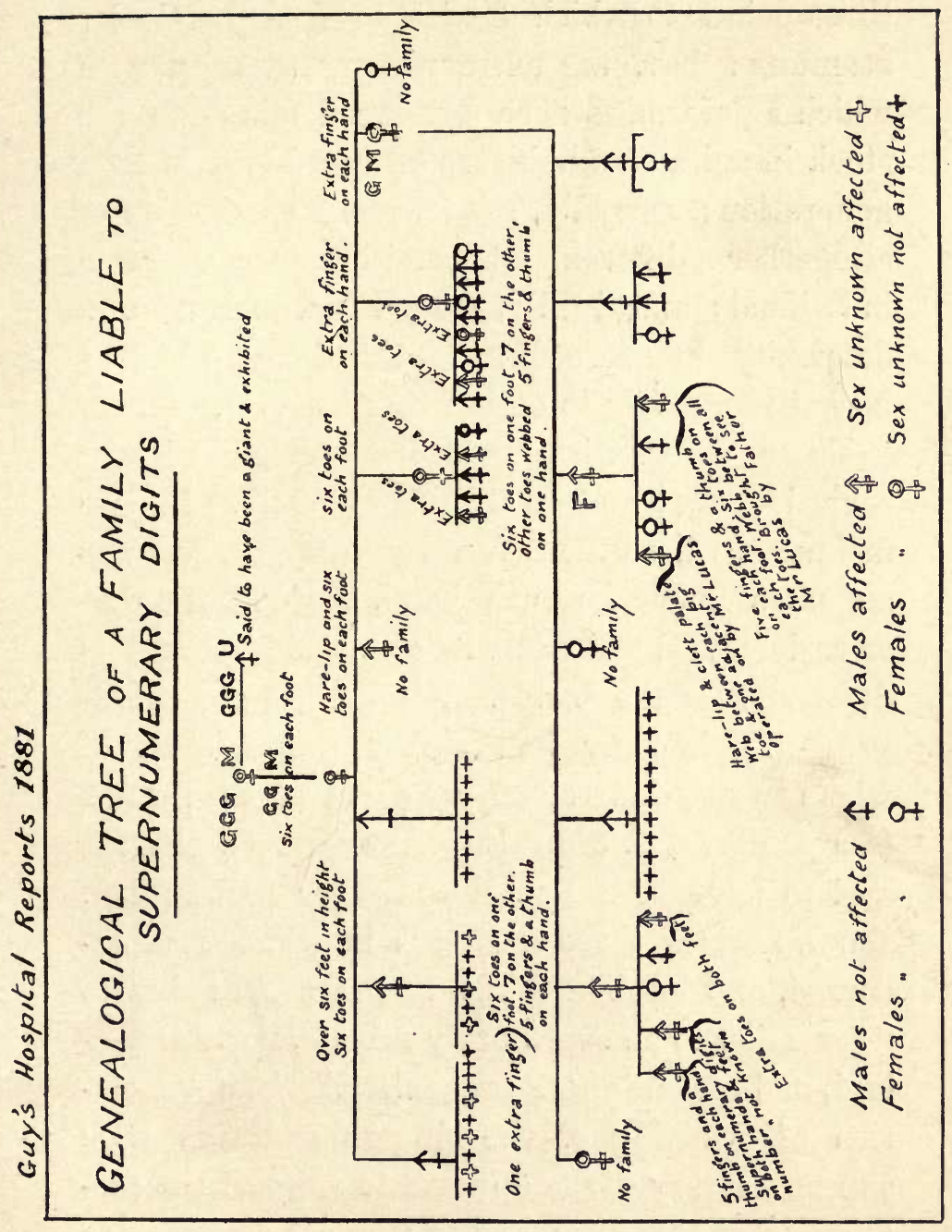


three points to which I wish to draw particular attention: first, the extraordinary tenacity with which a deformity once developed clings to the stock in spite of admixture of new blood in each generation ; secondly, the frequent association of altogether different deformities in the same individual; and thirdly, the gradual increase of a deformity in succeeding generations, which I intend more fully to enter into presently.

These deformities were transmitted without regard to sex, and it will be noted that in two instances, where the deformity in the mother was an extra finger on each hand, the children that were deformed had extra toes on each foot and no deformity of the hands. Altogether, the greatgreat-grandmother had eighty descendants, of whom twenty-four, or 30 per cent., were deformed (see pedigree, p. 31). Supernumerary digits are said to have been reproduced after amputation. Darwin gives three instances in which this occurred, and explained the recurrence as due to "reversion to an enormously remote, lowly organised, and multidigitate progenitor." The association of webbing of the fingers and toes with supernumerary digits appears to support the correctness of this view, and to suggest reversion to some highly remote amphibious ancestor. 


\section{Tenacity of Deveropment of Deformity.}

With regard to the first point, the tenacity with which a defect or deformity once developed persistently clings to a stock, and is repeated generation after generation, in spite of new blood being infused, there are pedigrees innumerable now to prove. Cannot a defect ever be washed out in its early beginnings by normal blood? My own small studies in search of hidden deformities appear to show their tendency is rather to increase than decline. The normal appears powerless to overcome the abnormal, or, as the Mendelians say, the deformity is dominant, and the normal recessive. The pedigrees of spade hands or brachydactyly recorded by Farabee and Drinkwater are claimed as clearly illustrating these features, the abnormal only giving origin to abnormals and the recessive normals yielding only normals. Nettleship's pedigree of congenital cataract is also claimed as following this law, but in some cases the defect was apparently transmitted through a normal. In future the closest attention should be applied to those exceptions, as from them new facts will probably be gathered. The best illustration we have of tenacity of descent of an abnormal condition is Cunier's ten generations of night-blindness. The descent appears to 
have been always carried on by an abnormal; but the numbers of normal and abnormal, which should be about equal, according to Mendel's law, when an abnormal unites with a normal, shows a great excess of normals above the Mendelian anticipation.

\section{Mulitiple Abrormalíies.}

The frequent association of different abnormalities, apparently quite unconnected, in the same individual, is another point deserving close attention and careful study. It would seem that the developmental process having once started in an abnormal direction may fail in its complex details at many points. Mr. Jackson Clarke published a case of clubbed hand due to absence of the radius associated with macrostoma in the first volume of the 'Reports of the Society for the Study of Disease in Children.' In the same volume the late Dr. George Carpenter published an account of two sisters, each of whom had a keel-shaped skull, congenital heart disease, ventral ruptures, webbed fingers, and six toes on each foot, and was also mentally weak. The mother was strong and healthy, and showed no deformity; but a cousin, the child of a maternal uncle, had deformed hands. In the second volume Dr. 
Hutchison and Dr. Sutherland published the cases of two unrelated boys presenting exactly the same deformities in association, viz.:

Congenital heart disease, (2) a rudimentary harelip, (3) six digits on each hand, (4) shortening of the long bones of the extremities, and (5) defective development of the gums. Many other similar cases of multiple deformities might easily be added; but I have mentioned sufficient, I hope, to stimulate research into the origin of this failure of control of the developmental process in so many directions.

Gradual Increase of Deformi'jes in Succeeding Generations.

The last point to which I desire to draw particular attention is the origin of deformities from small, easily overlooked, beginnings. I feel sure a search for these will add much to our knowledge, and it may be possible, by recognising the forerunners, to prevent the development of the graver deformities. Among minor deformities the crooked little finger, which can easily be shown to be tenaciously hereditary, has been treated almost with scorn by Mendelians. Professor Bateson writes : 
This peculiarity may descend both through the affected and through the unaffected, but the affection, I believe, is like that seen in chickens, whose feet may be deformed through weakness. . . Pedigrees of such peculiarities cannot be expected to give results of much positive value.

I take a diametrically opposite view and regard these minor deformities as those from which most will be gathered in the future, regardless of whether they conform to theory or not.

\section{Weismann's Theory.}

Several families in which this defect dwells I have kept in view for years, and finding it practically confined to the middle and upper classes I used to teach, before Weismann's theory swept the field of Lamarckism, that it was probably brought about by generations of cramping of the little finger in writing and by gloving. The adhesion between the little and ring finger I thought might have been brought about in the same way: But Weismann has come and gone with his theory of the complete independence of germ-plasm and body-plasm, so that the effect of environment, use or disuse, upon any part of the body is not reflected, according to his theory, in the germ-plasm, and consequently not hereditary. His theory failed to account for the reproduction of lost parts, such as the salamander's tail, which 
is said to have been reproduced as many as ten times after amputation, and he was obliged to admit that certain influences, such as lack of nourishment, might influence and modify the germ-plasm which he regarded as continuous. His theory led to a discovery of inestimable value - the finding of the chromosomes of the nucleus, their reduction to half their normal number, and the restoration to the normal number on fertilisation, half being supplied by the germ- and half by the sperm-cell. But his theory has probably swung the pendulum of thought too much in one direction, and though it may be true that body influences of a few generations are not evident in the offspring, when we are dealing with hundreds, thousands, or millions of generations the effects of use and disuse seem to me scarcely to be denied. Perhaps no better illustration can be given than the gradual changes that are taking place in the human foot. It is twenty-three years ago that in a lecture on anatomy I pointed out that the gradual disappearance of the little toe was getting ahead of the text-books, for whilst it had already lost one of its extensor tendons, in quite an appreciable percentage of cases one of its flexor tendons was absent also. These at best, like its bones, are diminutive and useless, and its 
joints are commonly ankylosed. On the other hand, the great toe has undergone extraordinary development, because the inner side of the foot is the first to catch the centre of gravity in transferring the weight of the body from one foot to the other in walking; and I ventured to predict that if the world went on long enough, in perhaps half a million of years, as the useless outer toes being less and less employed gradually disappeared, man might become a one-toed race. FIG. 4.

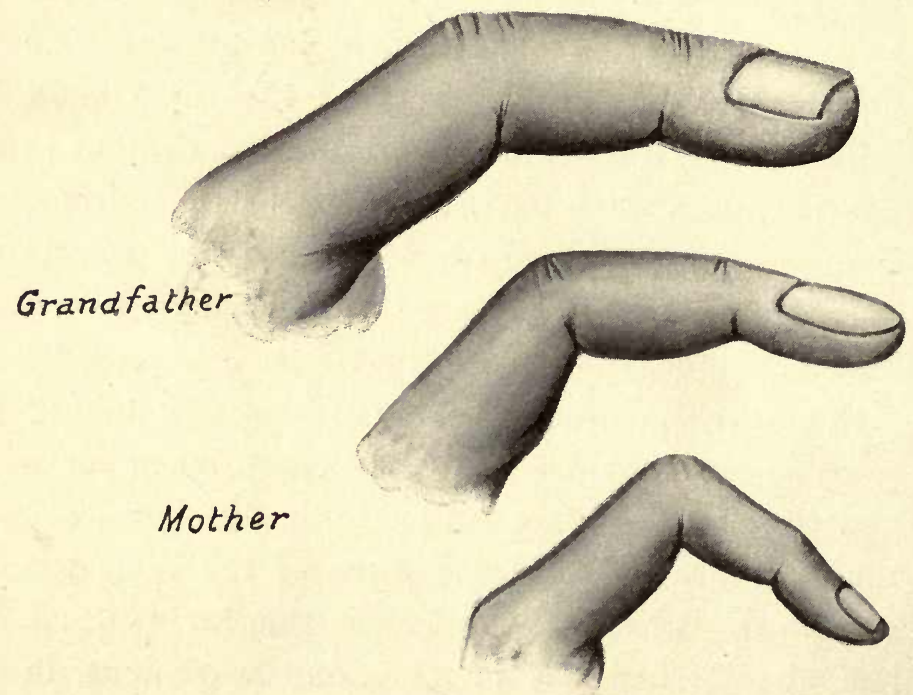

Daughter

From this digression into which allusion to Wiesmann's theory has tempted me, I return to 
the crooked little fingers and I throw on the screen a sketch showing the gradual increase of this defect in three generations. It is highly probable that Nature throws out warning signals of danger in the early stages of many hereditary deformities which may be discovered if a careful search be made for minor defects among the immediate ancestors.

Relation of the Absence of, or a Defective, Lateral Incisor. Tooth to Hare-lip and Cleft Palate in Later Generation.

I have only worked this out in the relation of the lateral incisor tooth to hare-lip and cleft palate, but I refer to it in order to stimulate younger observers to turn their attention to this important study, and I have one further observation as yet unpublished. My attention was first drawn to it by observing that a gentleman who, as a boy, was noticed to have an absence of the left lateral incisor tooth, had an only daughter who presented precisely the same defect on the same side. As this only child has never married there was no chance of proving the relation to hare-lip and cleft palate in that family. It proved, however, that the defect could be transmitted, and that the transmission might be through the opposite sex. Next, an infant was brought among my out-patients suffering from hare-lip on 
the right side. This was the fifth child of a mother aged twenty-five years. The mother's lip was perfect but she had an absence of the lateral incisor tooth of the right side which had never been extracted and was known never to have developed. The third case was the first child of a delicate woman, aged twenty-three years. The mother had absence of the left lateral incisor, which she was certain had never been extracted; her infant had left-sided hare-lip and completely cleft palate.*

Further observations led to the discovery that FIG. 5.

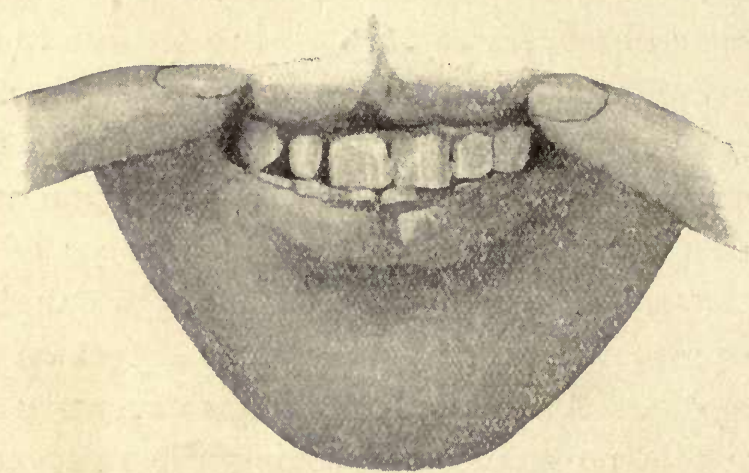

Mouth of mother showing small right upper lateral incisor tooth and scar of hare-lip. Her child had right side hare-lip and completely cleft palate.

an ill-developed lateral incisor tooth might foretell hare-lip and cleft palate in the offspring. A * 'Clin. Soc. Trans.,' 1888, p. 64. 
mother who showed the scar of a hare-lip on the

Fig. 6.

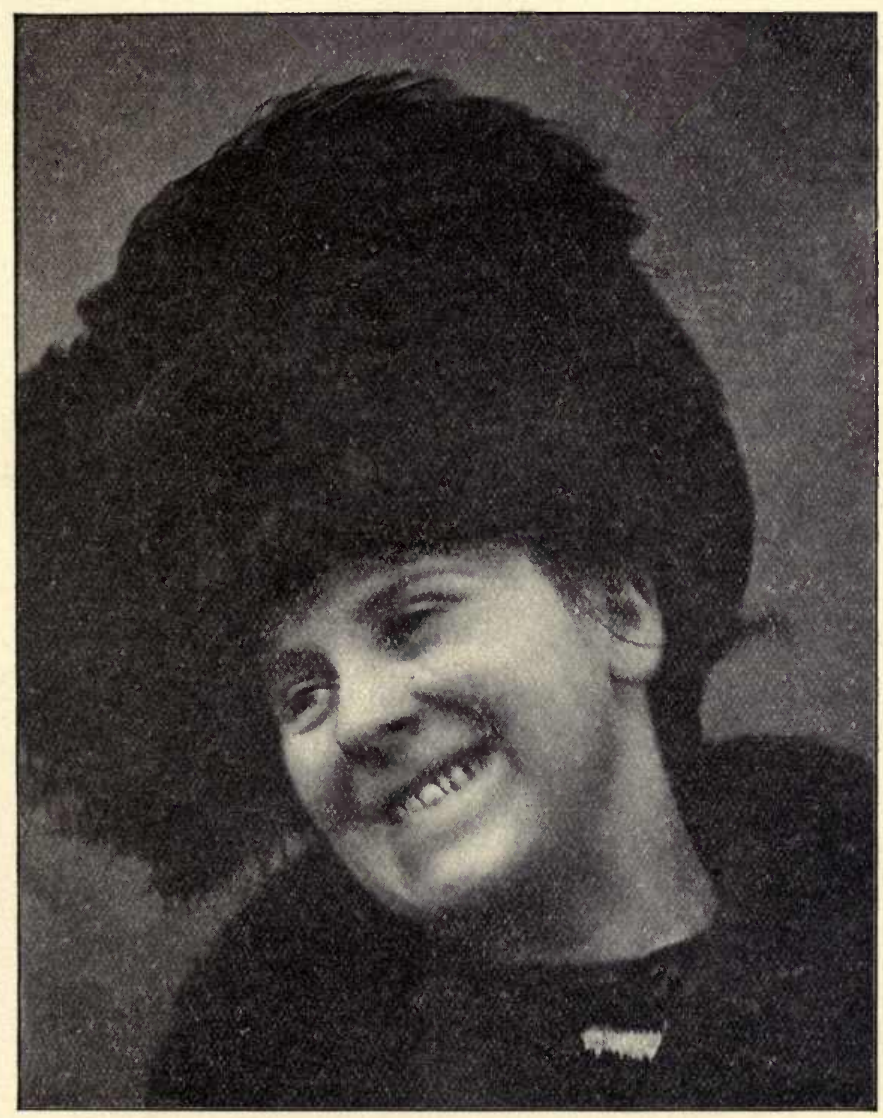

Mother with a defective lateral incisor on left side. First child had left side hare-lip extending into the nostril.

right side but no defect of alveolus or palate was 
found to have an ill-developed lateral incisor on the right side. Her first child had an extreme deformity of hare-lip and cleft palate extending from the right side (see Fig. 5, p. 4.0). The next case was the first child of young parents who was brought for operation on a hare-lip on the left side extending into the nostril. The mother was a nice-looking woman and showed no defect in her lip, but on the left side her lateral incisor tooth presented a remarkably defective development. It will be noted that the defect in the child is invariably on the same side as the defect in the mother (see Fig. 6, p. 41).*

My last observation is on a young man who was operated on for hare-lip on the right side in infancy. On examining his teeth I found that the prospective division of the palate which did not proceed, or perhaps I ought to say lack of union, had divided his lateral incisor opposite the cleft into two separate small teeth (see Fig. 7, p. 4.3).

* 'Reports of the Society for the Study of Disease in Children,' 1905 , p. 31 . 
Fig. 7.

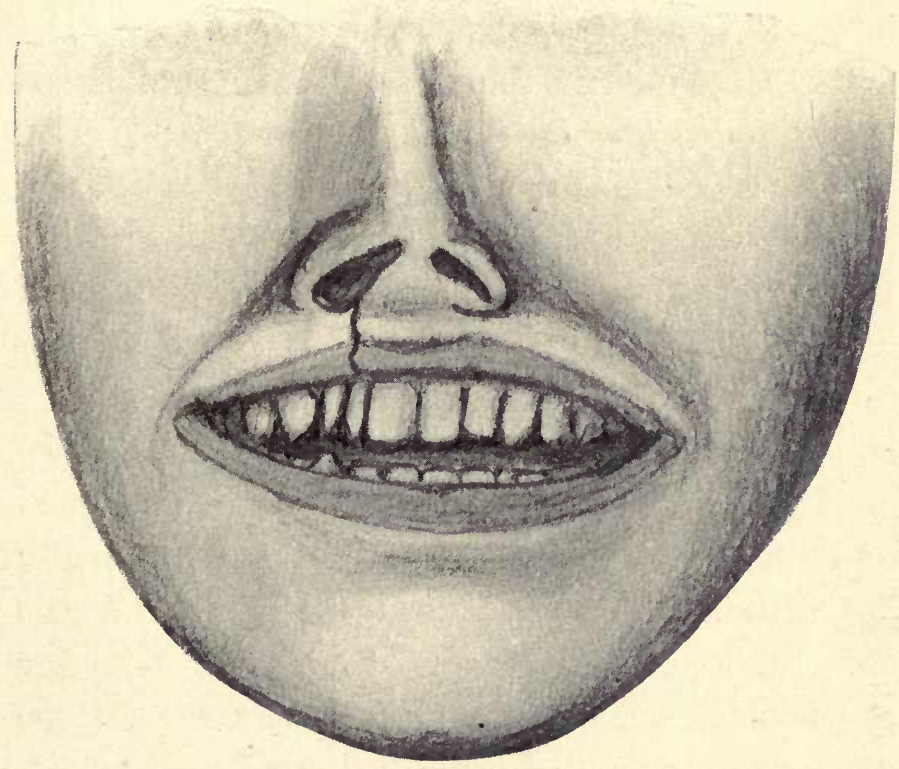

Youth, aged seventeen years, with right side hare-lip united by operation, showing lateral incisor split into two pegged teeth opposite the scar. The palate was normal. 


\section{ADDENDUM.}

The Results of the Assumption of the Erect Position.

The necessity of curtailing much that I had intended to allude to in order to bring the material within the limits of the allotted hour, prevented me from dwelling on those changes dependent on evolution and the assumption by man of the erect position which have long been a favourite study. I referred to the alterations that have taken place, and are still going on, in the human foot, merely to show that Lamarckism, which recognises the effects of prolonged use or disuse through many generations, offers yet the best explanation of such gradual changes; for it could scarcely be contended that natural selection and the survival of the fittest would alone or together account for these alterations in structure. The quadruminuous hind-hand when placed on its palmar surface for walking would find the abducted thumb (adducted in this position) too near the line of body gravity for safety against overweight and consequent dislocation. It therefore approached the forefinger for support, and its enormous metacarpal (becoming metatarsal) bone, in its growth, pushed up the web to the level of 
the other toes. The race for length has but recently been decided in favour of the great toe, for old sculptures show the second and third toes to be longer; and the great toe has been handicapped by having only two phalanges instead of three to grow from. Concurrently the carpal bones became changed and enormously strengthened to bear weight, the heel being thrust back and the metatarsal bones lengthened for better leverage, but the four outer toes, no longer of service in prehension and of little use as weightcarriers, diminish relatively to the rest of the foot and the little toe falls away relatively to the others. Only the base of its metatarsal bone is retained and specially developed for the attachment of two of the peronei muscles which serve to help balance the body on the foot. The fibula or ulna, pushed aside by the radius or tibia and allowed no share in weight carrying, is retained only for muscular attachments and to prevent outward dislocation at the ankle. With the growth of the heel and the forward displacement of the weight-carrying astragalus the leg becomes extended on the thigh and the thigh on the pelvis. The head becomes more evenly balanced on the top of the spine, and the spine becomes more firmly fixed by its wedge to the sides of the pelvis. The viscera grouped 
around the spine and supported by the pelvis retain, or should retain, much of their old positions. Such is a brief outline of the main changes brought about by the assumption of the erect position.

The Adap'ation of the Human Frame to the Erect Posimion.

After the thousands of centuries that the erect position has been assumed, can it be said that the human frame has completely adapted itself to the changed attitude? I think it must be admitted that it has not, and that there are many defects and liabilities that can be directly ascribed to the change of posture. I have been trying to think if there are to be found any common defects, frequent in quadrupeds and in man, that the erect posture has been beneficial in relieving, and I can only think of umbilical hernia. This defect is common in domesticated animals-cows, sheep, dogs, and to a less extent I think in cats. I have never noticed the defect in a horse, because, probably, a horse with such a condition is useless, and is destroyed and never used for breeding purposes. Umbilical hernia has in the lower animals, I believe, no tendency to cure itself. In man it is exceedingly common in infants, but 
tends, more than any other form of rupture, to disappear with increasing age. The recession of the liver from the level of the umbilicus to a position beneath the ribs and the pull of the round ligament upon the umbilicus have, no doubt, much to do with the cure; but I think it must be admitted that the relief from direct downward pressure which the erect posture assures has a potent influence in assisting the natural cure.

When we consider the various displacements and defects directly favoured by, and in many instances definitely due to, the erect position, we shall find that there is a long list to be enumerated. Among the solid viscera : (1) The dropping of the kidneys from their beds, at one time thought to be rare, but now known to be very common, is a condition largely due to the erect position. (2) 'The spleen, too, occasionally drags away from its anchors, and I have myself seen it occupy Douglas's pouch. (3) The uterus suffers in many ways: before impregnation from flexions and versions, and after childbirth from prolapse in addition to the other displacements.

The hollow viscera also tend to be displaced by the erect position. The transverse colon, overloaded with fæcal matter, is liable to drop down from its position along the margin of the ribs and 
to form a loop below the umbilicus with the concavity upwards, thus bringing about kinking at the lateral flexions. The various weak points at the lower part of the abdomen are subjected to greater strain, and inguinal, crural, obturator, vaginal, and sciatic herniæ are rendered more frequent. The bladder and ovary may also occasionally be found in a hernia.

Outside the abdomen we notice varicocele caused by the weight of a loaded sigmoid upon the spermatic vein, where it is exposed to pres. sure on the brim of the pelvis; hæmorrhoids associated with rectal accumulations and varicose veins in the legs are common in those whose occupations require that they should stand for many hours in succession. These defects are very definitely associated with the assumption of the erect posture.

Knock-knee and flat-foot, bow-legs and weak ankles are the result of the assumption of the erect position before the supporting tissues have gained sufficient strength to bear the bodyweight, or, perhaps, more often result from defective feeding and hygiene, by which the bones, ligaments and muscles are weakened relatively to the strain put upon them when carrying the body in the erect position. 


\section{APPENDIX.}

Since. delivering my lecture at the Royal College of Surgeons my attention has been drawn to the "identical twins," Myrtle and Violet Smith, daughters of Mr. George Smith, of Waltham Cross, who has kindly forwarded to me their photographs and a record of their school life. In answer to the question as to heredity, $\mathrm{Mr}$. Smith writes: "I am a twin myself, the other died, and one of my sisters had twins but they both died."

Each of these twins put in seven years' perfect attendance at school, being never absent and never late, which indicates unusual health, as well as unusual regularity. In this way each obtained three medals, a silver watch, and a certificate for Scripture. They also obtained forty-three prizes at day and Sunday schools. Their resemblance, as indicated in the photograph (see Fig. 8, p. 50), is so great that among persons who know them well, one is frequently mistaken for the other. 


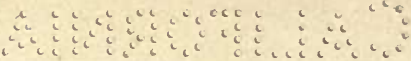

'THE BRADSHAW IEC'TURE

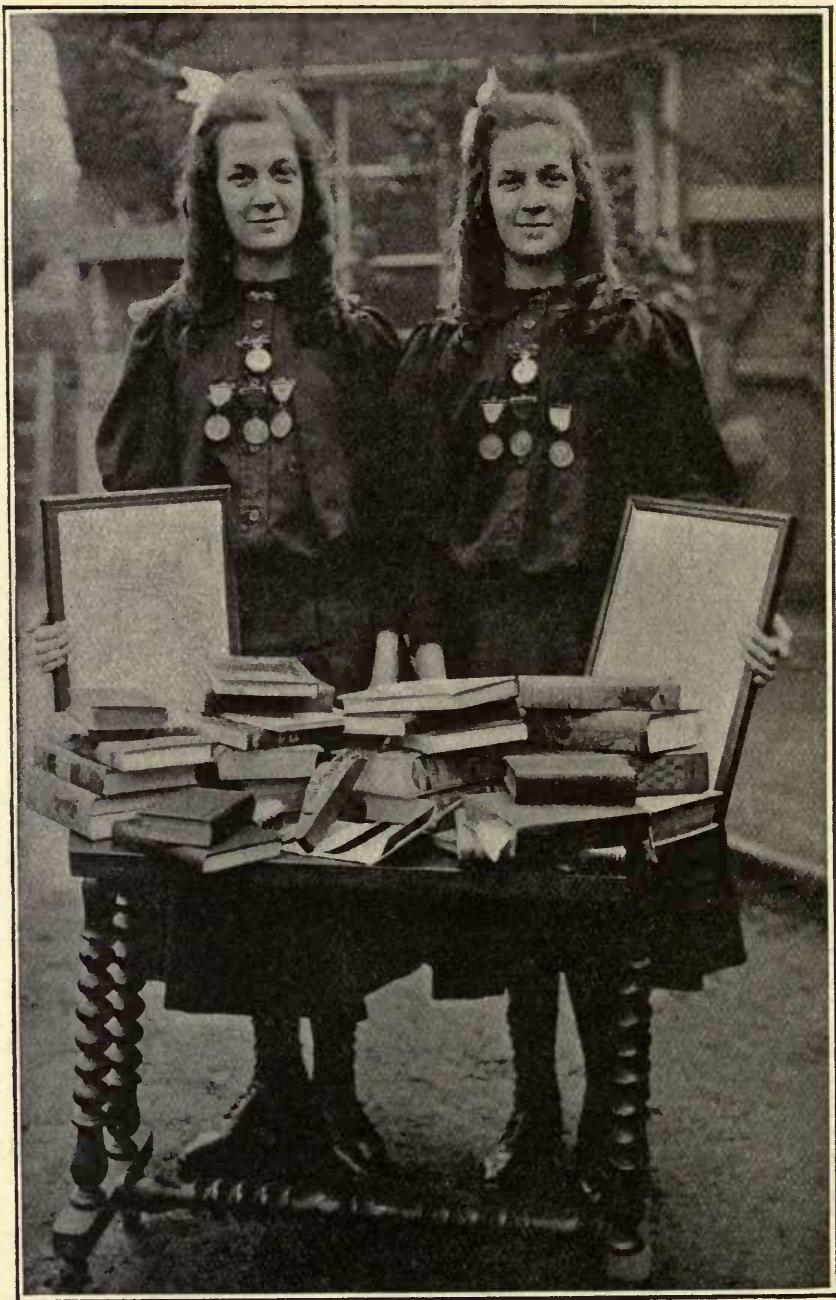

MYRTLE.

VIOLET.

ADLARD AND SON, IMPR., LONDON ANI) DORKING. 



\section{UNIVERSITY OF CALIFORNIA LIBRARY}

BERKELEY

\section{THIS BOOK IS DUE ON THE LAST DATE STAMPED BELOW}

Books not returned on time are subject to a fine of $50 \mathrm{c}$ per volume after the third day overdue, increasing to $\$ 1.00$ per volume after the sixth day. Books not in demand may be renewed if application is made before expiration of loan period.

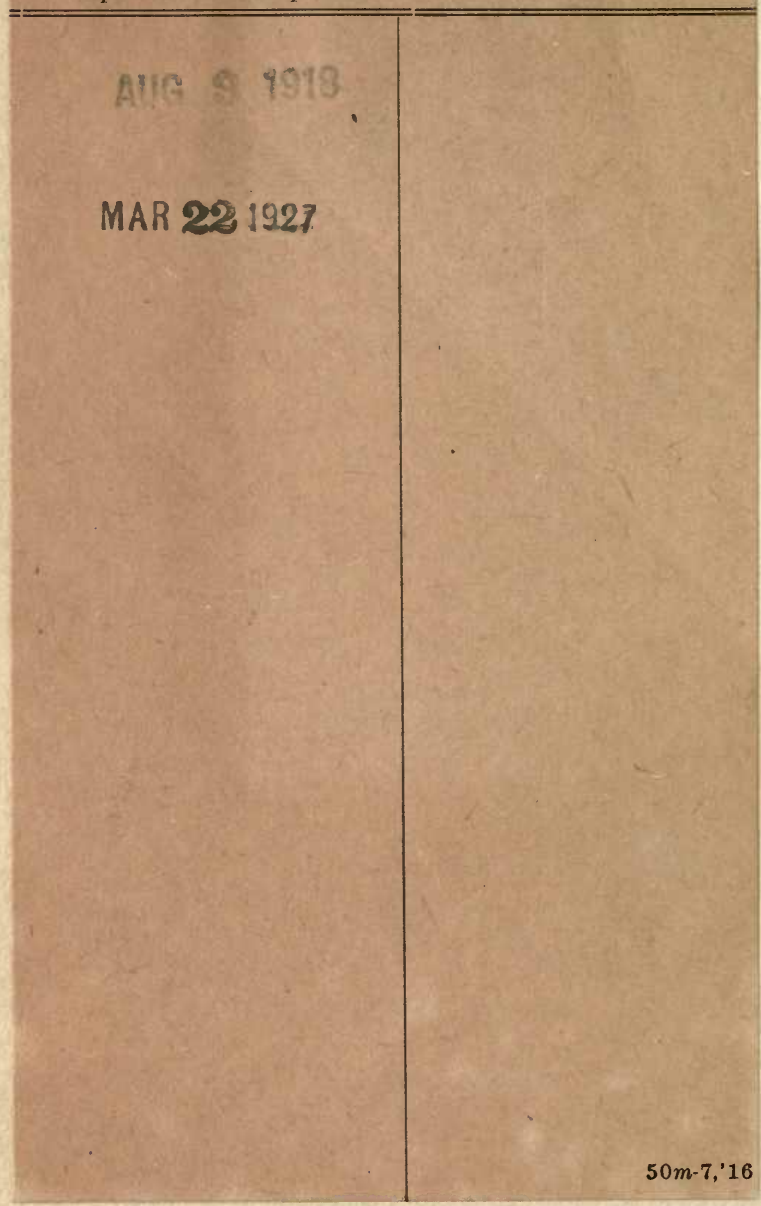




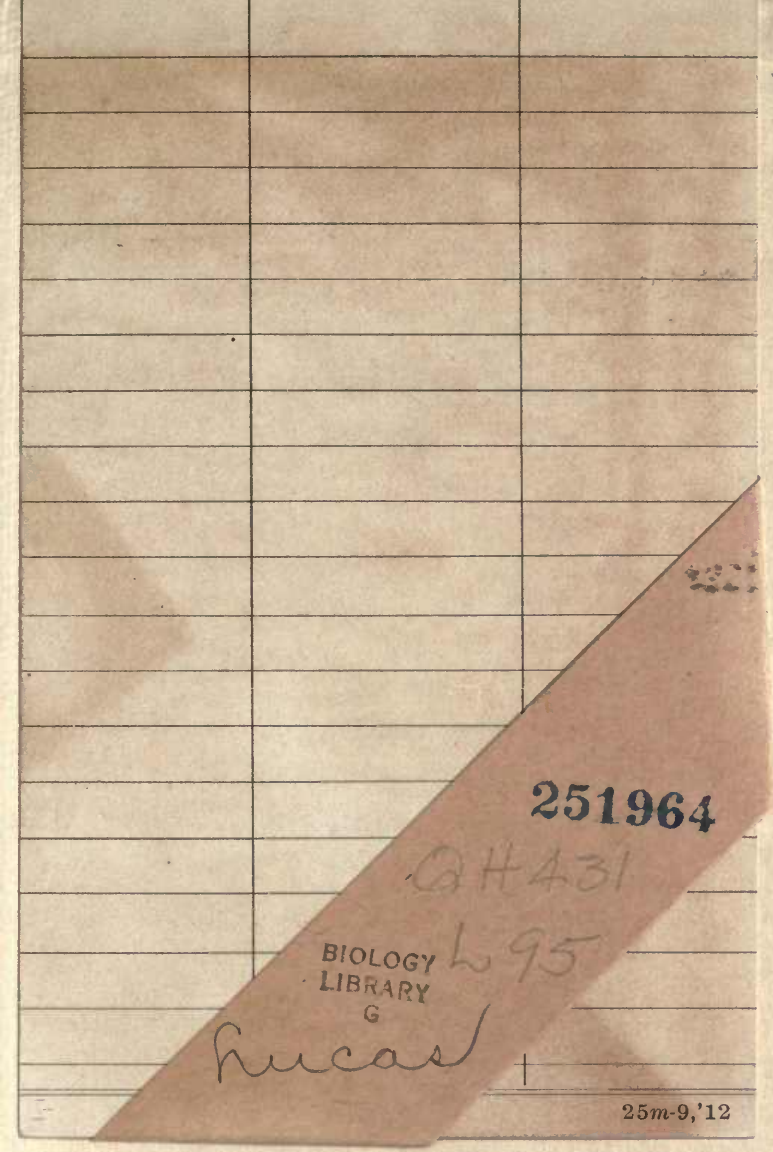


